\title{
SaskPharm: a proposal for provincial drug production
}

$\mathrm{R}$ ecent months have seen a renewed call to attenuate the runaway costs in the least controlled segment of the health care system: prescription drugs. In 2009, Canadians spent $\$ 30$ billion $^{1}$ on pharmaceuticals.

There has been much discussion of how we should pay for prescriptions: individually, both out-of-pocket and through insurance plans, or collectively through taxation. An oft-neglected, related issue is the question of who makes the medications. Many are available in generic forms, produced at a fraction of what it cost the original manufacturers. Generic companies then sell the medications at a relative fraction of the discount, which is to say that the profit margin on generic drugs is very high.

Leaving aside for a moment who will pay for medications, what if governments made them?

In Saskatchewan, as in many provinces in Canada, there is a long history of successful Crown corporations. They effectively and profitably provide essential services such as vehicle insurance, telephone services and electricity, and sport provincially patriotic names like SaskTel or SaskPower. Consider for a moment a hypothetical Crown corporation that produces generic drugs: SaskPharm.

By creating SaskPharm, the province could provide essential medicines to its population, create local jobs and save provincial health dollars. SaskPharm could produce and provide generic prescription drugs to Saskatchewan Health at cost, greatly decreasing procurement costs. These savings could be used for other aspects of the health care system or reinvested into research and development. Prescriptions of SaskPharm products could also be sold to the public at a moderate profit, somewhere between cost and the price of equivalent drugs from existing manufacturers. This would pass savings on to consumers while still providing operating and expansion capital. In addition, medications could be sold at bulk prices to other provinces and juris- dictions, along the lines of existing arrangements provincial governments have made with generic pharmaceutical companies. This would provide savings to other provincial governments while creating further revenue streams for SaskPharm.

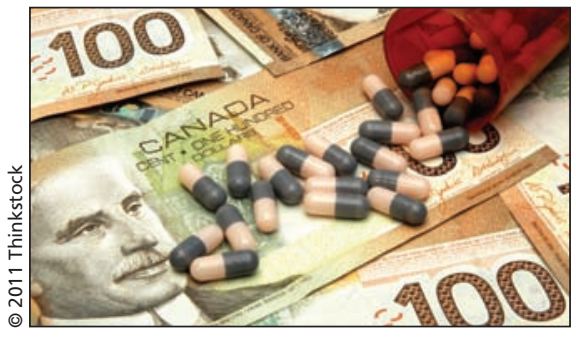

The potential economic benefits to such an approach are many. A Crown corporation like SaskPharm would provide jobs in research, medicine, information technology, commerce and other sectors, such as new markets for agricultural crops that can be used in medication production. The development of this economic niche could provide job opportunities for Saskatchewan's young, growing population and attract professionals and business people from elsewhere.

Should SaskPharm prove profitable in the production and sale of generic pharmaceuticals, there is also the potential for it to move into researching and developing new drugs. This is perhaps the most exciting aspect of this idea. Other pharmaceutical companies profit only through sales: if people stop getting sick, they stop making money. SaskPharm, as an arm of the provincial government, would profit by making or keeping people healthy. There would be a built-in incentive to create drugs specific to the health of the Saskatchewan people, such as new ways of monitoring or treating diabetes or helping to control the province's growing HIV epidemic. This would free up provincial funds for other priorities, as well as create potential for profit with sales of SaskPharm original medications to other jurisdictions.

As it did with the introduction of universal health insurance, Saskatchewan could once again, take a leadership role in health care by forming a Crown corporation to produce and develop new medications. Saskatchewan tends to be an ideal place for this sort of experiment: its market is large enough to warrant the investment, yet small enough that change would not be exceedingly cumbersome.

Clearly this sort of innovation is not without its challenges. The initial startup costs, including market studies, establishing business plans, obtaining accurate scientific information and methods of production, personnel, and eventually building a production site would require a major financial commitment. Eventually, however, these costs would be offset by provincial savings in mediation costs and the aforementioned modest profit on sales to consumers.

Extreme care would also have to be taken in relation to patent laws and trade agreements to be certain that there was no legal backlash. Competition would be fierce and we could expect bitter marketing and legal battles, though that would be attenuated somewhat by the lack of existing competitors in drug production in Saskatchewan. But, at the risk of being rhetorical, these risks are certainly no greater than those faced by our predecessors when introducing Medicare (which began in one province and eventually expanded to the entire country). This is a different time, to be sure, but there still exists an appetite for inventive, evidence-based solutions in public policy. SaskPharm is a homegrown way of controlling drug costs in Saskatchewan. It bears exploring. And perhaps CanPharm, and better health for Canadians at a lower cost, will be the eventual result.

\section{Ryan Meili MD}

College of Medicine

University of Saskatchewan

Saskatoon, Sask.

\section{Reference}

1. Canadian Institute for Health Information. Drug expenditure in Canada, 1985 to 2009. Ottawa (ON): The Institute; 2010.

CMAJ 2011. DOI:10.1503/cmaj.101814

All editorial matter in CMAJ represents the opinions of the authors and not necessarily those of the Canadian Medical Association. 